\title{
Assessing the Reliability and Validity of Attitudes and Confidence Scales for the Care of Women and Girls Affected by Female Genital Mutilation/Cutting
}

\section{Christina X. Marea ( $\nabla$ cflemi10@jhu.edu )}

Georgetown University School of Nursing and Health Studies https://orcid.org/0000-0003-3820-2452

Nicole Warren

Johns Hopkins University School of Nursing

Nancy Glass

Johns Hopkins University School of Nursing

Crista Johnson-Agbakwu

Arizona State University

Nancy Perrin

Johns Hopkins University School of Nursing

Research article

Keywords: Female Genital Mutilation/ Cutting, Female Circumcision, Health Care Provider, Attitudes, Confidence, Validation

Posted Date: December 15th, 2020

DOl: https://doi.org/10.21203/rs.3.rs-126815/v1

License: (c) (1) This work is licensed under a Creative Commons Attribution 4.0 International License.

Read Full License

Version of Record: A version of this preprint was published at BMC Public Health on July 17th, 2021. See the published version at https://doi.org/10.1186/s12889-021-11455-8. 


\section{Abstract}

Background: Approximately 545,000 women and girls in the USA have undergone Female Genital Mutilation/ Cutting (FGM/C) or have mothers from a country where FGM/C is practiced. Women and girls living with $\mathrm{FGM} / \mathrm{C}$ in the USA may experience stigma and bias due to their FGM/C, immigration, racial, and language status. Health care provider attitudes toward FGM/C and confidence for related clinical care may affect the quality of care, yet there are no validated instruments.

Methods: We developed the instruments via review of the FGM/C literature, the development of scale items, expert review, and pre-testing. We validated the instruments using a convenience sample of providers in Arizona and Maryland. We used exploratory factor analysis (EFA) to confirm factor structures, and compared scores between known groups to assess validity.

Results: The EFA revealed a two-factor solution for attitudes, including subscales for Negative Attitudes and Empathetic Attitudes toward FGM/C and those who practice with Cronbach's alphas of 0.814 and 0.628 respectively. The EFA for confidence revealed a two-factor solution including Confidence in Clinical FGM/C Care and Confidence in Critical Communication Skills for FGM/C Care with Cronbach's alphas of 0.857 and 0.694 respectively.

Conclusions: Health care provider attitudes and confidence toward FGM/C care may affect quality of care and health outcomes for women and girls. Our study describes the rigorous psychometric analysis to create reliable and valid instruments to assess health care provider attitudes and confidence for the care of women and girls who have experienced FGM/C.

Trial Registration: Clinical Trials.Gov ID \# NCT03249649, Study ID\# 5252. Public website: https://clinicaltrials.gov/ct2/show/NCT03249649

\section{Background}

Female Genital Mutilation/ Cutting (FGM/C), a cultural practice with no health benefits, involves the cutting and/or removal of parts of the external female genitalia. According to UNICEF and the World Health Organization (WHO), FGM/C is practiced in certain communities across approximately 31 countries in Africa, the Middle East and South Asia, with its prevalence varying dramatically between and within countries. $(1,2)$ Motivations for the practice are diverse and may relate to beliefs about cleanliness, sexual norms, rites of passage, marriageability and/or group membership.(3-5) The WHO has enumerated 33 possible health complications associated with $\mathrm{FGM} / \mathrm{C}$, which range from immediate postFGM/C, physiological (obstetric, gynecologic, sexual) to psychological impacts.(2) The WHO has classified FGM/C into four major types depending on the extent of tissue cut or removed and whether the vaginal opening is also narrowed. While all FGM/C types are associated with health complications, not everyone who has undergone FGM/C will experience them. Women with more extensive or severe cutting tend to have worse morbidity.(6) In 2016 and 2018 respectively, the WHO published Guidelines on the Management of Health Complications from FGM and Care of Women and Girls Living with FGM: A 
Clinical Handbook which provide comprehensive guidance on the clinical care for those living with $\mathrm{FGM} / \mathrm{C} .(2,7)$

Estimates from 2012 indicate that 545,000 women and girls living in the United States of America (USA) may have either undergone FGM/C or were born to mothers from a country where $\mathrm{FGM} / \mathrm{C}$ is practiced-an increase of $224 \%$ since 1990.(8) As women and girls from families that practice FGM/C are born in or migrate to settings where the practice is non-normative, they may interact with healthcare providers who are unaware of $\mathrm{FGM} / \mathrm{C}$, or who do not have the training and confidence to provide evidence-based care. Even if a health care provider is confident in their ability to provide quality care, they may hold attitudes that create barriers in the patient-provider relationship.(9) Health care providers who encounter a patient with FGM/C may experience a strong affective response including anger toward the practice of $\mathrm{FGM} / \mathrm{C}$, or bias toward women who experienced it.(10) USA providers and patients with FGM/C may further face challenges with cross-cultural communication exacerbated for those with low-English proficiency, particularly if the provider is not skilled conducting visits via interpreter.(11-13) Disagreements about treatment and difficulties in communication can result in a lack of confidence in and distrust of providers by the patients. $(14,15)$ Some women with FGM/C prioritize minimizing interventions; this may be perceived by providers, who may not have actively listened to the patient's perspective or priorities, as antagonistic or ignorant. $(16,17)$ Health care providers may experience frustration when patients express distrust or refuse recommended care.(12) Women and girls who have experienced FGM/C deserve quality care, yet evidence suggests that they often do not receive it.(16, 18-21)

According to the WHO, quality care is effective, efficient, accessible, patient-centered, equitable, and safe. (22) Current studies of health care providers and their patients affected by FGM/C show that FGM/Crelated care is often ineffective and inequitable due to a lack of provider knowledge, training and confidence in their ability to provide appropriate care for FGM/C-related complaints. $(10,11,23)$ For example, a recent meta-synthesis of the birth experiences of FGM/C-affected women in the context of migration revealed anxiety and fear related to their pervasive perception that health care providers do not know how to care for them.(16) Women with FGM/C often distrust health care providers who they feel lack the knowledge and confidence to provide high quality care for FMG/C related complaints. $(16,23-$ 28) This distrust can result in women with $\mathrm{FGM} / \mathrm{C}$ being less likely to seek or access reproductive health care(29) or to decline recommended care.(12) Providers who are knowledgeable about FGM/C have likely learned while caring for patients with FGM/C, rather than received training in advance. $(30,31)$

\section{Existing Measures of Attitudes and Confidence for FGM/C- Related Care}

Health care provider attitudes and confidence impact the quality of care received by patients affected by FGM/C, yet there are few existing instruments to measure these constructs. We conceptualized attitudes as the expression of an individual's tendency of favor or disfavor expressed toward a particular entity to inform our instrument development.(32) In drafting our attitudes items, we reviewed existing measures created for use in high resource countries where FGM/C is not normative. Existing measures are 
characterized by the lack of psychometric assessments to determine their reliability or validity. Authors use no $(33,34)$ or limited validation procedures including expert review(35-37) and pre-testing. $(31,35,36$, $38,39)$ Existing measures tend to include items that focus on ethical issues related to FGM/C (e.g., whether adult women have the right to elect $\mathrm{FGM} / \mathrm{C}$, the respondent considers $\mathrm{FGM} / \mathrm{C}$ a violation of human rights, parents have the right to elect to choose FGM/C for daughters). $(31,38,40,41)$ The items assessing attitudes towards ethical issues tended to have agree/ disagree Likert scale type responses. Some items included in existing attitudes measures actually capture knowledge (e.g., whether $\mathrm{FGM} / \mathrm{C}$ is a religious or cultural practice), or contextual questions (e.g., whether FGM/C is legal in their jurisdiction, if there are mandatory child protective services reporting requirements, and whether they are aware of parents who intend to have FGM/C for a daughter locally or by traveling abroad [vacation-cutting]).(41) Additional attitudes items asked respondents to state how they would respond to a patient affected by FGM/C.(42) These types of items measure intentions to act that may be influenced by attitudes, rather than measuring the attitude itself.

Existing measures of attitudes tend to focus on attitudes toward FGM/C as a practice, rather than attitudes towards the women, girls, and communities that are affected by or support FGM/C or towards the provision of FGM/C-related care. Negative attitudes toward those affected by FGM/C are important to measure because a health care provider's negative attitude toward a person on the basis of irrelevant characteristics such as race or language proficiency (also known as implicit bias) has been shown to negatively affect clinical care including diagnosis, treatment decisions, health outcomes, non-verbal behaviors, and patient-provider interactions. $(43,44)$ Most women and girls affected by FGM/C in the USA are of African, Asian or Middle Eastern descent - groups where $50-75 \%$ of individuals surveyed report experiencing bias or discrimination in the health care setting. $(44,45)$ People of color report reduced experiences of bias when they have a health care provider who shares their racial or ethnic identity.(44, 46) Women and girls who have experienced FGM/C embody multiple identities that, within the USA, can render them vulnerable to bias and discrimination including immigration/ refugee status, low-English proficiency, and being a person of color. $(9,43,47)$

We began of development of the confidence items by confirming an operational definition and reviewing existing measures. Self-reported confidence in a particular skill is also termed self-efficacy and can explain, in part, the actual performance of that skill.(48) Self-efficacy is the perceived capability to perform a behavior and is a robust predictor of whether someone will engage in a target behavior.(49) We identified only two studies since 2007 that assessed health care provider confidence for FGM/C-related care. Both measures lack conceptual definitions of confidence nor do they explain the rationale behind item development. $(34,37)$ Items in one existing study encompassed multiple concepts, thereby limiting interpretability because it is unclear which component of the item respondents considered in their responses.(34) Despite limitations, many concepts were important to consider for our measure including confidence in discussing defibulation, identification and management of FGM/C, documentation, and counseling. $(34,37)$ 
The current literature on health care provider attitudes and confidence would be strengthened by measures that utilize clear conceptual definitions of attitudes and confidence, have undergone psychometric testing, and enable researchers to explore the relationships between attitudes, confidence, and other provider characteristics. In this study, we describe the development and psychometric assessment of novel measures of attitudes and confidence of health care providers caring for women and girls affected by FGM/C.

\section{Methods}

\section{Instrument Construction}

Authors CM (Nurse-Midwife) and CJA (OB/GYN) discussed the attitudes- and confidence-related domains that emerged from the literature review and considered their own experiences providing care for patients affected by FGM/C. We sought to develop attitude items that may affect quality of care for patients who have experienced $\mathrm{FGM} / \mathrm{C}$ including attitudes toward the practice of $\mathrm{FGM} / \mathrm{C}$, and the women, girls and communities that are affected by the practice. We included items that expressed both negative and empathetic attitudes. We thought of negative attitudes as those that might lead the provider to express, or a patient to experience, discrimination or bias related to their $\mathrm{FGM} / \mathrm{C}$ status. Empathetic attitudes might lead the health care provider to prioritize a patient-centered approach to FGM/C-related care.

We determined that there were broadly two areas of confidence that directly influenced the effectiveness, and equitable patient-centered delivery of care to patients affected by FGM/C: confidence in the provision of clinical FGM/C care, and confidence in the ability to communicate effectively with patients who have experienced FGM/C. Ideally, we would directly observe provider care; however, given the ethical and practical challenges, we elected to use self-reported confidence as a proxy measure. Items related to clinical care included identifying $\mathrm{FGM} / \mathrm{C}$, determining its type, documenting its presence, discussing potential complications, and management. Critical communication skills for care of patients affected by FGM/C include the ability to effectively conduct visits via an interpreter, offer evidence-based treatment options, maintain rapport with a patient who is declining recommended care, and engage in nonjudgmental listening.

\section{Expert Review and Pre-Testing}

Clinical FGM/C experts including an obstetrician/ gynecologist, a nurse-midwife, and a pelvic floor physical therapist reviewed the attitudes and confidence items for content validity. We circulated a shared document adding comments and edits that were integrated by $\mathrm{CM}$. Comments included grammatical adjustment, clarifying wording to avoid jargon, and simplifying sentence structure. One attitudes item was dropped because it contained multiple clauses and thus responses were not interpretable. No other items were added or dropped. Next, a nurse-midwife and medical resident who are not FGM/C experts reviewed the instrument for clarity and understandability while seated with $\mathrm{CM}$. CM inquired what they thought each question was intending to ask to ensure that their interpretation was consistent with our intention. No issues arose during this review, and no further revisions were suggested. The survey was 
then pre-tested among a convenience sample of 3 medical students, 2 medical residents, and 2 nursemidwives with no previous FGM/C-related training in current clinical practice in the Phoenix and Baltimore-DC areas. The full survey took approximately 7-10 minutes to complete. No further edits were suggested.

\section{Study Setting}

We conducted an online cross-sectional survey of health care providers at the time of registration in a workshop titled "Optimizing Care for Women and Girls Affected by FGM/C" in the greater Phoenix and Tucson, Arizona and Baltimore, Maryland areas. This workshop and study were conducted as part of a multi-phase study that aimed to identify and address gaps in care for women and girls affected by Female Genital Mutilation/Cutting (FGM/C).

\section{Recruitment and Study Population}

Health care providers were invited to register for the workshop and complete the survey via emails that were distributed to list-servs at 14 health care institutions in Phoenix and Tucson, Arizona metropolitan areas. Arizona list-servs included between 80-400 contacts. The survey was broadly distributed within the Johns Hopkins Health System and Johns Hopkins University Schools of Medicine, Nursing and Public Health as well as to professional organizations in the greater Baltimore, Maryland and Washington D.C. area. The primary list-serv contacts included nursing and residency training program directors, medical directors, nursing and medical faculty, and hospital department chairs, and points of contact for local chapters of professional organizations such as AWHONN, ACNM, and ACOG.

The study population included health care providers who registered for the workshop and completed the online survey at the time of registration. A broad sample of health care providers registered for the workshop and completed the baseline survey, including physicians, residents, nurses, nurse-practitioners, nurse-midwives, physicians assistants, mental health workers, social workers, and students in the health professions.

\section{Measures}

The survey included information about the study, an electronic consent form, demographic, clinical practice, and previous FGM/C related clinical experience. The Health Care Providers Attitudes Toward FGM/C and Those Who Practice scale included twelve items total, with five that assessed negative and seven that assessed empathetic attitudes. See table \#1 for all Attitude items. The Health Care Providence Confidence in FGM/C Care measure included five items that assessed FGM/C-related clinical care and three items that assessed confidence in communication for FGM/C care, including listening, counseling, and interpreter use. See Table \#2 for all confidence items. For both the Attitudes and Confidence scales, participants were asked to read each statement and then mark their level of agreement with the given statements on a four-point Likert-scale from “ 4 = Strongly Agree” to " 1 = Strongly Disagree." 
Table 1

Health Care Providers Attitudes - Items

\section{$1 \quad \mathrm{FGM} / \mathrm{C}$ is a violation of human rights}

2 Communities that practice $\mathrm{FGM} / \mathrm{C}$ are oppressive towards women.

3 Health Care Providers who perform any form of FGM/C, including symbolic nicking, should be charged with a crime.

$4 \quad$ Parents who have their daughter circumcised are abusing them.

5 Women who have undergone FGM/C are victims of an oppressive cultural practice.

6 Symbolic nicking or cutting of the female genitalia is an effective way to reduce the harm of FGM/C compared to more extensive procedures.

7 Communities that practice FGM/C are honoring an important cultural tradition.

8 Adult women have the right to undergo FGM/C.

9 Parents who have their daughter circumcised are protecting her future marriage prospects.

10 Women who have undergone FGM/C are empowered agents.

11 Parents have the right to have their daughters circumcised (undergo FGM/C).

12 Health care providers should perform reinfibulation (re-closing of the vulvar scar following childbirth) if the woman requests it.

Table 2

Health Care Provider Confidence - Items

\section{On inspection of the female genitalia, I can identify a woman with FGM/C}

2 On identification of a woman with FGM/C, I can assign the appropriate WHO Type classification

3 On identification of a woman with FGM/C, I can appropriately code a visit to document the presence and type of FGM/C using ICD-10 and CPT codes

4 Conduct an effective reproductive/sexual health history via an interpreter

5 Respond to the health concerns of women with FGM/C by engaging in non-judgmental listening

6 Counsel women on the possible complications she may experience related to FGM/C

7 Discuss defibulation with pregnant women who have undergone Type 3 FGM/C in a culturally sensitive manner

8 Create a positive therapeutic relationship with a patient who refuses a recommended procedure

\section{Statistical Methods}


We used SPSS version 26 for the analysis. We examined construct validity for each scale using exploratory factor analysis (EFA) with principal axis factoring and oblimin rotation. Factor loadings above 0.40 were considered as loading on a given factor, and those below were considered for revision or elimination from the scale. We reviewed the items loading on each factor to ensure they comprised interpretable constructs and distinct subscales. We used Cronbach's alpha to assess the reliability of each subscale.

We assessed validity by comparing known groups using independent t-tests; $\mathrm{p}$-values $<0.05$ were considered significant. For the attitude scales, we tested the a priori hypotheses that health care providers 1) with previous FGM/C training; 2 ) who have ever cared for a patient affected by FGM/C; 3 ) who identify as nurses, social workers, or mental health specialists; 4) whose clinical practice focuses on women's health; 4) who are of color; and 6) who are women will have less negative attitudes and more empathetic attitudes toward FGM/C and those who have experienced FGM/C. For the confidence scale, we tested the a priori hypotheses that those 1 ) who have had previous FGM/C training; 2 ) who have cared for a patient affected by FGM/C; and 3) whose clinical practice focuses on women's health will have greater confidence in the care of those affected by FGM/C.

\section{Results}

\section{Enrollment and Participant Characteristics}

A total of 796 individuals registered for training events in Arizona and 101 in Maryland for 897 possible survey participants. A total of 369 participants initiated the online survey, of whom 14 did not provide any responses following the informed consent screen. The remaining 354 participants completed the online survey for a response rate of $39.5 \%$. Exploratory factor analysis requires that all participants have completed all items to be included in the analysis. For the Attitudes scale, 291 (82.2\%) participants completed all items and were included in the EFA. For the Confidence scale, we limited analysis to health care providers who are licensed independent providers (LIP), defined as physician or advanced practice nurses ( $n=169,47.7 \%$ of the total sample). These providers conduct the outpatient medical care that Confidence scale items address. Of the LIPs $n=143$ (84.6\%) completed all Confidence items. There were no significant differences in any participant characteristics between completers and non-completers. Participants for the attitudes EFA sample were predominantly female (81.4\%), white $(67.5 \%)$, and had a clinical specialty outside of women's health (65.0\%). Demographics were similar for the attitudes and confidence sub-groups; however, the subsample for confidence scale EFA more participants were white $(77.6 \%)$ and had a women's health focus in their clinical practice (52.4\%). See table \#3 for detailed participant characteristics. 
Table 3

Participant Characteristics

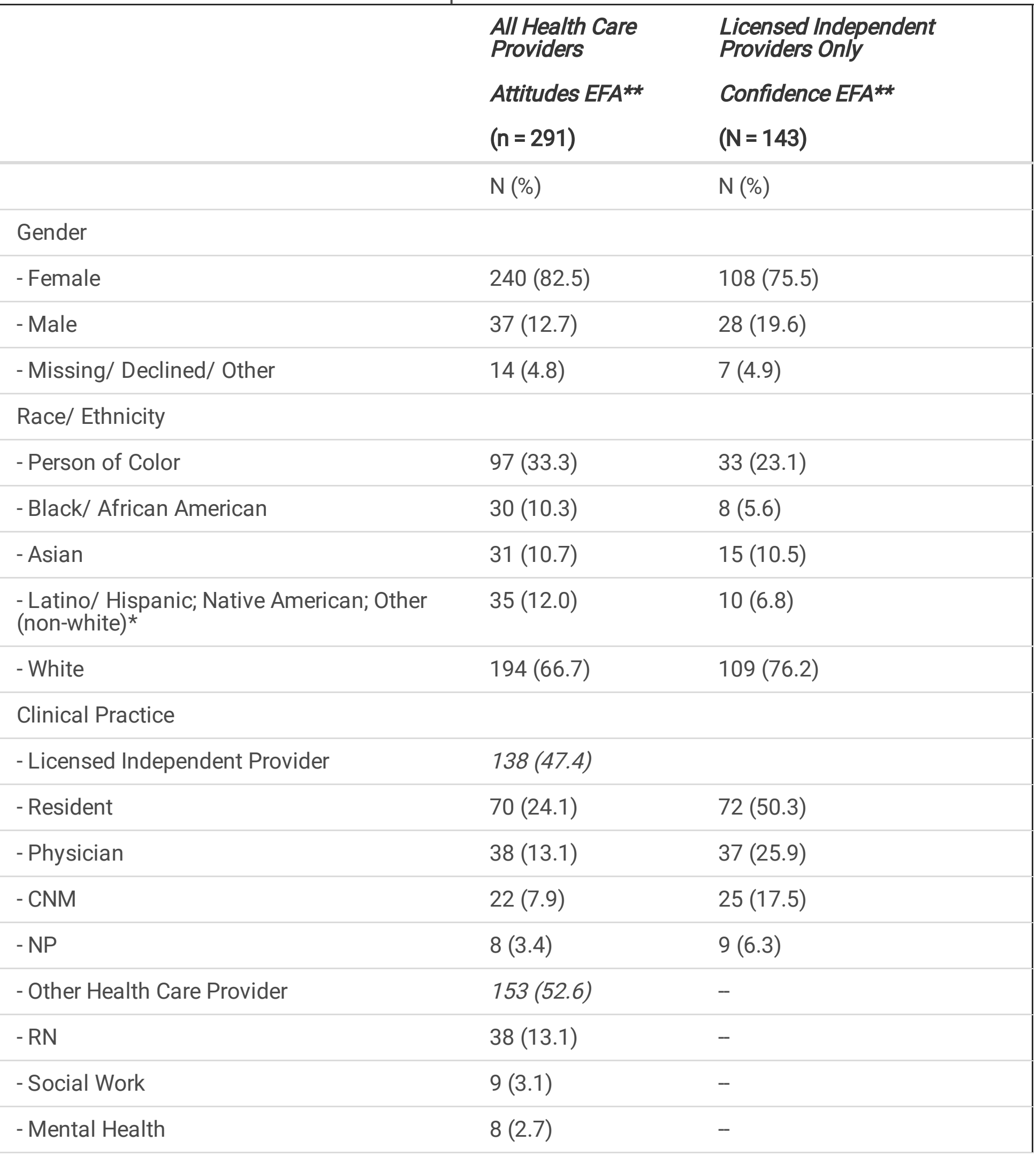

*Due to small sample size for these demographic groups, they were combined to protect participant privacy.

**Demographics for participants who completed all items for the respective scale. 


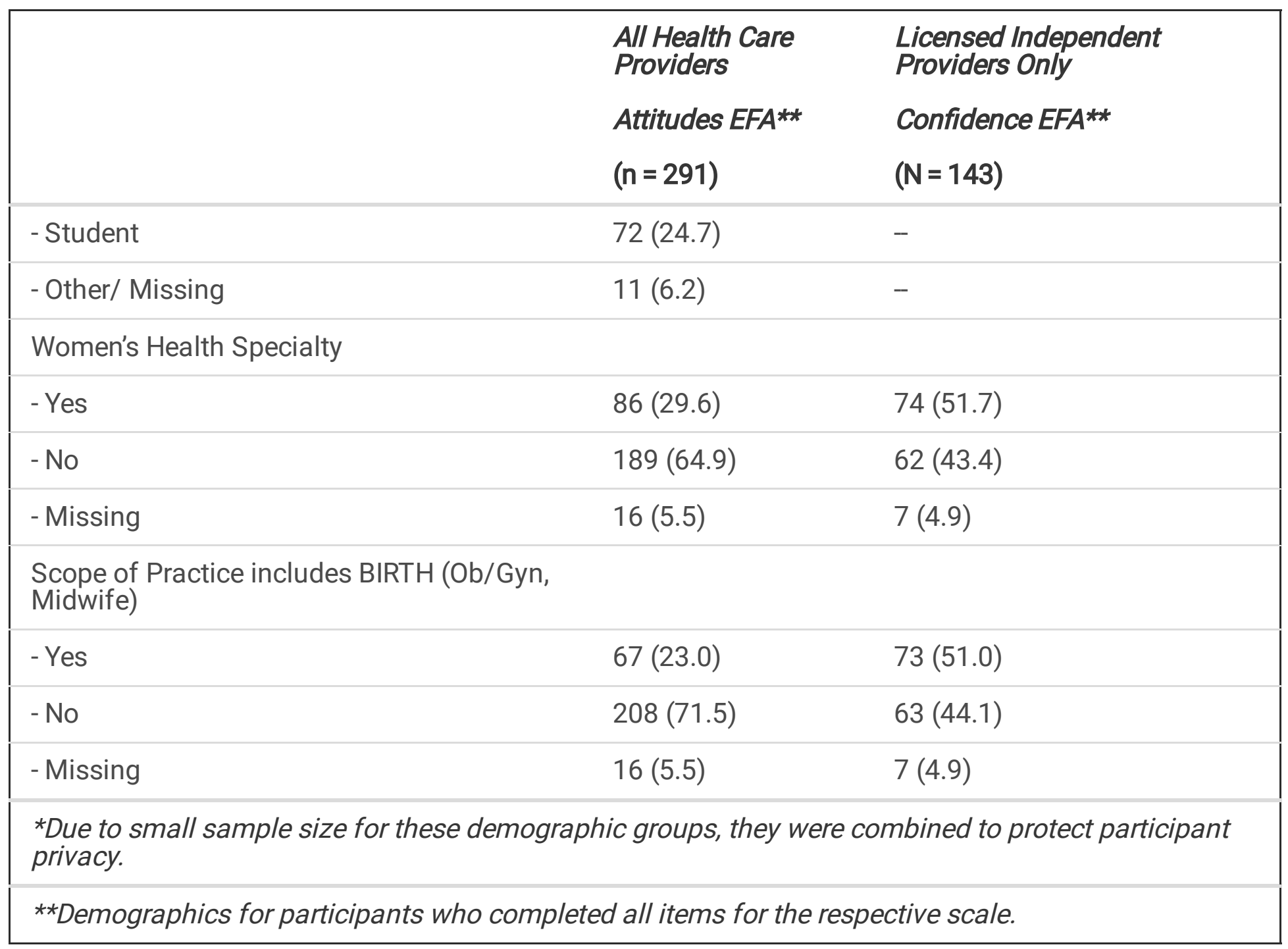

Fewer than half of the sample of health care providers had ever cared for a woman or girl who had experienced FGM/C (44.0\%), though among the subsample of licensed independent providers two-thirds had $(69.4 \%)$. Most participants had not received any formal training regarding FGM/C. See table \#4 for additional details about the FGM/C related clinical experiences of the participants. 
Table 4

FGM/C Clinical Experiences

\begin{tabular}{|lll|}
\hline & $\begin{array}{l}\text { Attitudes EFA } \\
\text { All Health Care } \\
\text { Providers } \\
(\mathbf{n = 2 9 1 )}\end{array}$ & $\begin{array}{l}\text { Confidence EFA } \\
\text { Licensed Independent Providers } \\
\text { Only } \\
\mathbf{( N = 1 4 3 )}\end{array}$ \\
\hline $\begin{array}{l}\text { Ever Cared for Patient with } \\
\text { FGM/C } \\
\text { - Yes }\end{array}$ & $128(44.0)$ & $99(69.2)$ \\
- No & $163(56.0)$ & $44(30.8)$ \\
\hline $\begin{array}{l}\text { Previous FGM/C Training } \\
\text { - Yes }\end{array}$ & $101(34.7)$ & $64(44.8)$ \\
- No & $190(65.3)$ & $79(55.2)$ \\
\hline
\end{tabular}

\section{Results - Psychometric Testing for Attitudes}

We began the exploratory factor analysis by reviewing the cases for completeness which demonstrated 3$9.9 \%$ missing responses per item. No items were eliminated due to missingness. We reviewed the variance of each item and eliminated one item because it had minimal variance with greater than $93 \%$ responding either disagree/ strongly disagree (Parents have the right to have their daughters circumcised/ undergo $F G M / C$ )). The lack of variance in this item may be because FGM/C is commonly considered a violation of human rights in the USA. The eigenvalues (first 5 were $3.72,1.39,1.07,1.03$, 0.84) suggested that the 11 items formed two factors, which we confirmed using a scree plot visualization to identify the two factors above the break in the plot. See figure \#1 for the Scree Plot.

All factor loadings were above 0.400 on only one of the two-factors except for Women who have undergone FGM/C are empowered agents which had a factor loading of 0.390 and was retained for the final subscale. The two-factor solution accounted for $37.5 \%$ of the total variance. Each item loaded cleanly on one of the two factors, except for Health care providers should perform reinfibulation (reclosing of the vulvar scar following childbirth) if the woman requests it which did not load on either factor and thus was dropped. This item likely did not perform well in the EFA because many participants may be unfamiliar with the term reinfibulation. See table $\# 5$ for the rotated factor loadings for the Attitudes items.

Items loaded according to whether they addressed negative or empathetic attitudes toward FGM/C and those who are affected by FGM/C (further referred to as Negative Attitudes and Empathetic Attitudes for brevity). Each subscale has five items. The correlation between the factors is -0.558 which indicates that the factors have a strong correlation but represent distinct underlying variables that are inversely correlated. The communalities for all items range from $0.173-0.624$. 
Table 5

Rotated Factor Loadings - Attitudes Items

\begin{tabular}{|c|c|c|}
\hline & $\begin{array}{l}\text { Negative Attitudes } \\
\text { Toward FGM/C and } \\
\text { Those Who Practice } \\
\text { FGM/C }\end{array}$ & $\begin{array}{l}\text { Empathetic Attitudes } \\
\text { Toward FGM/C and } \\
\text { Those Who Practice } \\
\text { FGM/C }\end{array}$ \\
\hline $\mathrm{FGM} / \mathrm{C}$ is a violation of human rights & .593 & -.066 \\
\hline $\begin{array}{l}\text { Health Care Providers who perform any form of } \\
\text { FGM/C, including symbolic nicking, should be } \\
\text { charged with a crime }\end{array}$ & .455 & -.099 \\
\hline $\begin{array}{l}\text { Communities that practice FGM/C are } \\
\text { oppressive towards women }\end{array}$ & .809 & .101 \\
\hline $\begin{array}{l}\text { Parents who have their daughter circumcised are } \\
\text { abusing them }\end{array}$ & .804 & .039 \\
\hline $\begin{array}{l}\text { Women who have undergone FGM/C are victims } \\
\text { of an oppressive cultural practice }\end{array}$ & .766 & -.041 \\
\hline $\begin{array}{l}\text { Symbolic nicking or cutting of the female } \\
\text { genitalia is an effective way to reduce the harm } \\
\text { of FGM/C compared to more extensive } \\
\text { procedures }\end{array}$ & .024 & .444 \\
\hline Adult women have the right to undergo FGM/C & -.025 & .440 \\
\hline $\begin{array}{l}\text { Communities that practice FGM/C are honoring } \\
\text { an important cultural tradition }\end{array}$ & -.028 & .557 \\
\hline $\begin{array}{l}\text { Parents who have their daughter circumcised are } \\
\text { protecting her future marriage prospects }\end{array}$ & .043 & .637 \\
\hline $\begin{array}{l}\text { Women who have undergone } \mathrm{FGM} / \mathrm{C} \text { are } \\
\text { empowered agents }\end{array}$ & -.044 & .390 \\
\hline Cronbach's Alpha & 0.814 & 0.628 \\
\hline \multicolumn{3}{|l|}{ DROPPED ITEM } \\
\hline $\begin{array}{l}\text { Health care providers should perform } \\
\text { reinfibulation (re-closing of the vulvar scar } \\
\text { following childbirth) if the woman requests it }\end{array}$ & -.121 & .244 \\
\hline
\end{tabular}

\section{Reliability}

We assessed the reliability of the subscales using Cronbach's alpha - a measure of internal consistency of the items as they perform in a specific sample. The Empathetic Attitudes subscale has a Cronbach's alpha of 0.628 . This meets the 0.60 threshold considered the minimum acceptable for early stages of 
research. $(50,51)$ Further, Cronbach's alpha tends to underestimate the internal consistency of scales with fewer than 10 items such as ours. $(52,53)$ The Negative Attitudes subscale has a Cronbach's alpha of 0.814 which is considered an acceptable level of internal consistency.

\section{Descriptive Statistics}

We calculated total scores for each subscale by summing scores for each of the five items. Higher scores indicate more negative attitudes and more empathetic attitudes on each scale respectively. See table \#6 for means, standard deviations, minimum and maximum observed scores

Table 6

Attitudes - Descriptive Statistics

\begin{tabular}{|lllllll|}
\hline$(\mathbf{n = 2 9 1 )}$ & Mean & Std. Dev. & Min & Max & $\begin{array}{l}\text { Possible } \\
\text { Range }\end{array}$ \\
\hline & & & & & & \\
\hline Negative Attitudes Toward FGM/C & 15.85 & 2.65 & 10 & 20 & $5-20$ \\
\hline Empathetic Attitudes Towards FGM/C & 11.75 & 2.37 & 5 & 20 & $5-20$ \\
\hline
\end{tabular}

The mean score on the Negative Attitudes was 15.85 (SD 2.65) out of 20 indicating that the sample tended to agree or agree strongly with statements that convey negative attitudes toward $\mathrm{FGM} / \mathrm{C}$ and those who affected. The range of scores for the Negative Attitudes subscale was between 10-20 with a roughly normal distribution of scores. The mean score on the Empathetic Attitudes was closer to the midrange of possible scores $(11.75$, SD 2.37) indicating that participants tended to agree or disagree with the statements, rather than holding strong opinions on either end of the response range. The range of scores for participants on the Empathetic Attitudes subscale included the full possible range from 5-20.

\section{Known Groups Validity}

We assessed validity by comparing scores between known groups using independent t-tests. There were no significant differences in scores on the Negative Attitudes or Empathetic Attitudes scales between those who had received training or ever care for patient with FGM/C compared to those without those experiences. Licensed independent providers (MD/ CNM/ NP) had significantly higher scores on the Negative Attitudes scale and significantly lower scores on the Empathetic Attitudes scale compared with nurses and mental health providers which supports our hypothesis. Scores were not significantly different on either scale for participants with a clinical focus in women's health. Male participants and white participants both had significantly higher scores on the Negative attitudes scale which supports our hypotheses; however, there were no significant differences in scores on the Empathetic Attitudes scale for either of these two groups. See table \#7 for detailed known group validity analysis. 
Table 7

Criterion Validity - Attitudes

$(n=291)$

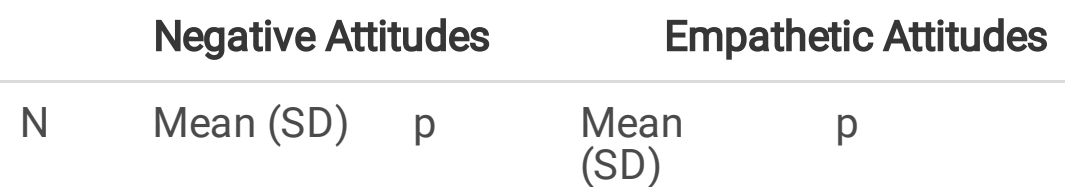

\section{PREVIOUS FGM/C EXPERIENCES}

Ever Cared for FGM/C-Affected

Patient

- Yes

$\begin{array}{llll}16.05 & 0.259 & 11.73 & 0.943 \\ (2.53) & & (2.42) & \end{array}$

- No

163

15.69

11.75

(2.74)

(2.34)

Received FGM/C Training*

- Yes

- No
101
15.75
0.652
11.96
0.262
190
(2.41)
(2.31)
15.90
11.63
(2.77)
(2.40)

\section{SCOPE OF PRACTICE}

Nursing and Mental Health

Providers

- Yes

149

15.51

0.031

12.19

(2.30)

0.001

- No

141

(2.77)

11.30

16.18

(2.36)

Women's Health Specialty*

- Yes

- No

86

16.00

189

(2.35)

$0.512 \quad 11.74$
0

(2.26)

0.915

15.79

11.78

(2.75)

(2.50)

\section{DEMOGRAPHIC}

Gender

- Male

- Female

$\begin{array}{llll}37 & 16.62 & 0.050 & 11.22 \\ & (3.06) & & (2.03) \\ 240 & & & \\ & 15.71 & & 11.88 \\ & (2.55) & & (2.37)\end{array}$




\begin{tabular}{|c|c|c|c|c|c|}
\hline$(n=291)$ & & & & & \\
\hline Race & & & & & \\
\hline - White & 194 & $\begin{array}{l}16.12 \\
(2.65)\end{array}$ & 0.014 & $\begin{array}{l}11.57 \\
(2.48)\end{array}$ & 0.078 \\
\hline - Person of Color & 97 & $\begin{array}{l}15.31 \\
(2.59)\end{array}$ & & $\begin{array}{l}12.09 \\
(2.12)\end{array}$ & \\
\hline
\end{tabular}

\section{*Unequal variance}

\section{Results - Psychometric Testing for Confidence Scale}

The psychometric analysis of the Confidence scale includes licensed independent providers (physicians, nurse-midwives, and nurse-practitioners). We began the factor analysis by reviewing the cases for completeness which demonstrated 4-9\% missing responses per item. We reviewed the item variance and found that Respond to the health concerns of women with FGM/C by engaging in non-judgmental listening and Create a positive therapeutic relationship with a patient who refuses a recommended procedure had minimal variance with $>91 \%$ selecting agree or strongly agree. We retained these items for the EFA because they addressed important aspects of quality care related to communication.

The EFA resulted in a 2-factor solution, which accounted for $50.87 \%$ of all variance. The eigenvalues (first five were $3.64,1.21,0.84,0.70,0.55)$ suggested that the eight items form two factors, which we confirmed using the scree plot to visualize two factors above the break in the plot. See Figure \#2.

All items had factor loadings over 0.400 and each item loaded on a single factor. See table \#8 for rotated factor loadings for the confidence items. The communalities range from 0.223-0.823. 
Table 8

Rotated Factor Loadings - Confidence Items

Confidence

in Clinical

Confidence in Critical

FGM/C Care Communication Skills for FGM/C Care

On inspection of the female genitalia, I can identify a woman with $\mathrm{FGM} / \mathrm{C}$

On identification of a woman with $\mathrm{FGM} / \mathrm{C}$, I can assign the appropriate WHO Type classification

On identification of a woman with $\mathrm{FGM} / \mathrm{C}$, I can appropriately code a visit to document the presence and type of FGM/C using ICD-10 and CPT codes

Counsel women on the possible complications she may experience related to $\mathrm{FGM} / \mathrm{C}$

Discuss defibulation with pregnant women who have undergone Type $3 \mathrm{FGM} / \mathrm{C}$ in a culturally sensitive manner

Conduct an effective reproductive/sexual health history via an interpreter

Respond to the health concerns of women with FGM/C by engaging in non-judgmental listening

Create a positive therapeutic relationship with a patient who is refuses a recommended procedure

Cronbach's Alpha

0.857

0.694

Principal Axis Factoring. Rotation Method: Oblimin Rotation.

The first subscale addresses items related the provision of clinical care of women who have experienced FGM/C, titled Confidence in Clinical FGM/C Care. The second subscale includes items that assess the health care provider's confidence in communication skills titled Confidence in Critical Communication Skills for FGM/C Care.

Reliability

The Cronbach's alpha coefficient for the two confidence subscales were 0.857 for the Confidence in Clinical FGM/C Care and 0.694 for Confidence in Critical Communication Skills for FGM/C Care, respectively, again indicating acceptable levels of reliability.

\section{Descriptive Statistics}

We calculated scores for the subscales by summing the scores for each item. The subscale Confidence in Clinical FGM/C Care has five items on a four-point Likert scale from strongly disagree $=1$ to strongly 
agree $=4$ for a possible score range of 5-20. The subscale addressing Confidence in Critical Communication Skills for FGM/C Care has three items on the same four-point Likert scale for a possible range of 3-12. Higher scores indicate more confidence. The correlation between the two factors is 0.461 which indicates that the subscales are positively correlated but do measure distinct latent constructs. See table \#9 for descriptive statistics.

Table 9

Descriptive Statistics - Confidence Scales

\begin{tabular}{|llllll|}
\hline$(n=143)$ & Mean & $\begin{array}{l}\text { Std. } \\
\text { Dev. }\end{array}$ & $\begin{array}{l}\text { Range } \\
\text { (possible) }\end{array}$ & Min & Max \\
\hline Confidence in Clinical FGM/C Care & 11.52 & 2.90 & $5-20$ & 5 & 20 \\
\hline $\begin{array}{l}\text { Confidence in Critical Communication Skills for } \\
\text { FGM/C Care }\end{array}$ & 9.08 & 1.35 & $3-12$ & 3 & 10 \\
\hline
\end{tabular}

The mean score on the Confidence in Clinical FGM/C Care subscale (11.52) indicates that participants generally endorsed a moderate level of confidence. The distribution of scores on this subscale is approximately normally distributed with slightly more participants reporting lower levels of confidence. The mean score on the Confidence in Critical Communication Skills for FGM/C Care subscale (9.08) indicates somewhat higher confidence in communication skills compared to clinical skills for FGM/C. The distribution of scores for this subscale is approximately normally distributed.

\section{Known Group Validity - Confidence Scales}

We assessed validity by comparing scores between known groups using independent t-tests. Health care providers who had ever cared for someone affected by FGM/C, had ever received FGM/C training, whose scope of practice includes a women's health specialty, people of color, and women rated their Confidence in Clinical FGM/C Care significantly higher than the comparison groups. Health care providers who have ever cared someone who had experienced FGM/C and those with a scope of practice focused on women's health had significantly high scores on the Confidence in Critical Communication Skills for FGM/C Care scales than the comparison groups. There was no significant difference in Confidence in Critical Communication scores for those who had received previous training related to FGM/C. See table \#10 for further details on validity testing. 
Table 10

Criterion Validity - Confidence Subscales

\section{$(n=143)$}

\section{Confidence in Clinical FGM/C Care}

Confidence in Critical Communication Skills for

FGM/C Care

$N \quad \begin{aligned} & \text { Mean } \\ & (S D)\end{aligned} \quad \mathrm{p} \quad$ Mean (SD) $\quad \mathrm{p}$

p

\section{PREVIOUS FGM/C EXPERIENCES}

Ever Cared for FGM/C-

Affected Patient

- Yes

99

12.51

(2.59)

44

$0.000 \quad 9.32(1.23)$

$.001^{\star}$

- No

9.27

$8.53(1.47)$

(2.25)

Received FGM/C Training

-Yes

64

12.32

(2.38)

- No

79

10.88

(3.12)

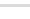


FGM/C, human rights) and add novel items to assess attitudes towards communities that practice FGM/C and affected patients.

The psychometric properties of the confidence subscales were strong overall. The subscales have a clear factor structure, and acceptable reliability. The validity of the Confidence in Clinical FGM/C Care is supported by the significance of the hypothesized group differences. The validity for the Confidence in Critical Communication Skills for FGM/C Care is supported by the significance of two of three hypothesized group differences. While we did not find a significant difference in confidence scores for those with and without previous FGM/C training in the Confidence in Communication subscale, this could potentially be a result of training programs focusing more on clinical skills than communication skills. There is very limited published data on existing trainings for FGM/C, and none we reviewed evaluated training effectiveness to improve communication skills.

The attitudes subscales also have clear factor structures, and the reliability of the $x$ subscale is acceptable. The reliability of the Empathetic Attitudes subscale falls just below the acceptable threshold. Cronbach's alpha has some limitations as a measure of reliability. It measures the internal consistency of the items within a specific sample, where more heterogenous populations tending to increase the Cronbach's alpha. Given that our sample was self-selected, they may be more homogenous in terms of attitudes toward FGM/C compared to the general population of health care providers. Our subscales also have a relatively small number of items $(<10)$, which can lower the Cronbach's alpha. The reliability of the scales should be further assessed in a random sample of health care providers. Future research should assess the reliability of these scales with a more diverse study population that varies in relation to demographic variables such as race, gender, and political affiliation; travel experience; and whether FGM/C has been practiced within their family or close contacts. Further validation of the scale could also include assessment of concurrent validity. Though there are no validated measures of attitudes related to FGM/C, comparing participants' scores on our scale with scores on validated measures of empathy and implicit bias may further inform the validity of the attitude scales.

There are some important differences between our subscales and existing measures. We did not include attitudes items that assessed whether participants believe $\mathrm{FGM} / \mathrm{C}$ is a religious practice or whether they knew their legal or reporting requirements because these questions address knowledge rather than attitudes. $(40,41)$ Our confidence scales included some similar concepts compared to existing measures including items addressing identification and documentation of $\mathrm{FGM} / \mathrm{C}$; however, our scales included more items regarding communication and counseling skills. $(34,37)$ Our scales are consistent with existing measures for attitudes and confidence by including items about defibulation and reinfibulation. $(31,34,38)$

Within the USA, many women and girls affected by FGM/C are migrants or refugees from Africa, Asia, or the Middle East who may have low-English proficiency - all variables that may contribute to experiences of bias, discrimination, and lower quality of care. The historical legacy of slavery and racism in the USA, and in particular the "othering" of African women's bodies, may implicitly influence the patient-provider 
interaction, counseling and decision-making.(9) Health care providers must take responsibility for communicating attitudes that promote positive patient/provider interaction so that FGM/C affected patients do not experience bias or discrimination during a clinical encounter. Our scales are an important step to assess health care provider attitudes toward FGM/C and those affected by the practice, and eventually to explore how their attitudes are related to patient experiences of care. The new attitudes subscales may allow researchers and educators to explore whether health care providers who experience more empathic and less negative attitudes provide higher quality care to patients affected by FGM/C. While empathy does tend to improve patient-provider communication, it is important to assess if health care provider empathy moves toward endorsement of harm reduction approaches to addressing FGM/C versus elimination of the practice.(54) Some health care providers maintain that the less extensive forms of $\mathrm{FGM} / \mathrm{C}$, such as symbolic nicking, should be permitted in place of more extensive cutting to minimize harm.(54-56) A recent case in Michigan where a doctor allegedly performed type $1 \mathrm{FGM} / \mathrm{C}$ in a clinic illustrates that $\mathrm{FGM} / \mathrm{C}$ diaspora communities and health care providers are negotiating these tensions within the USA.(57) By including items that assess strongly empathetic attitudes toward FGM/C, researchers and educators may be able to provide additional education to health care providers regarding the physical and ethical harm of cutting the genitals of a minor. Some argue that minors (child with male, female, or intersex genitalia) must be protected from bodily harm, which includes nontherapeutic genital surgery or cutting (including male circumcision).(58) Though these attitudes may be less common in the USA, our scales may detect the range of empathetic attitudes.

In our study sample, previous training in FGM/C was not a statistically significant predictor of increased Confidence in Communication for FGM/C. This may be because existing FGM/C trainings do not focus on communication skills, or if they do, may not provide an opportunity to practice those skills in order to measurably improve provider confidence.(59) Future trainings should include informational content about FGM/C (history and context, identification, documentation, complications, and management for patients affected by FGM/C) to build provider confidence in their knowledge to provide clinical care for FGM/C. Trainings should include opportunities for simulation, reflection, and engagement to practice applying knowledge, communications skills (including interpreter use), and build awareness of how attitudes may affect the quality of care delivered to those affected by FGM/C.(57) Broad health workforce education to improve the care of patients affected by FGM/C, including effective evaluation of education and training interventions, is an important public health priority.(57)

Some limitations of our study include geographic restriction of the study population to the greater Phoenix, Tucson, and Baltimore areas and a low response rate by the study population. We used a convenience sample for this analysis with participants who self-selected to register and complete the survey for an FGM/C training workshop, which could result in a bias related to their interest in the topic of FGM/C. Future studies may expand the geographical area of the study population and utilize different recruiting methods to reduce bias. As discussed previously, the Empathetic Attitudes subscale did not have strong reliability as measured by Cronbach's alpha. A future iteration of the Empathetic Attitudes scale with additional items in a random sample of health care providers may remedy this issue. Our study 
could have been strengthened by assessing concurrent validity of our subscale using a criterion measure; however, we were not able to identify any validated attitudes or confidence scales to use.

\section{Conclusion}

To the best of our knowledge, the attitude and confidence scales presented here are the first psychometrically validated measures to assess health care provider attitudes and confidence for the care of women and girls affected by FGM/C. Our confidence scales have strong validity and reliability, our attitudes scales have a clear factor structure, and the Negative Attitudes scale has strong reliability. Researchers may explore the relationship between health care provider attitudes and confidence for FGM/C related care with patient outcomes such as patient perceptions of quality of care (including experiences stigma and/or bias), trust in their provider, and receipt of appropriate diagnosis and treatment of FGM/C and associated health complications. Our measures will support future researchers to investigate factors that affect quality of care for women and girls who have experienced FGM/C.

\section{Abbreviations}

WHO - World Health Organization

FGM/C - Female Genital Mutilation/ Cutting

USA - United States of America

EFA - exploratory factor analysis

\section{Declarations}

\section{Ethics Approval and Consent to Participate}

This analysis includes a combined data set reflecting the locations where we conducted health care provider trainings (Arizona and Maryland). We received approval from the Arizona State University Institutional Review Board (IRB), and the Johns Hopkins Medical Institute IRB. Electronic consent was obtained from all participants. Participation was voluntary and anonymous. No incentives were offered.

Consent for Publication

Not applicable

Availability of Data and Materials

The datasets used and analyzed during the current study are available from the corresponding author on reasonable request.

Competing Interests 
The authors declare that they have no competing interests.

\section{Funding}

This study was funded by a grant from The Department of Health and Human Service/Office on Women's Health (grant number \# ASTWH160045-02-00)

\section{Authors' Contributions}

CXM is the main researcher who designed the study and led the writing process. CXM and CJA conducted data collection. CXM and NP performed the data analysis. CJA, NP, NW, and NG contributed to the conceiving of the study, the data analysis and writing process. All authors read and approved the final manuscript.

\section{Acknowledgements}

We thank Karoun H. Bagamian for her writing and editorial suggestions.

\section{References}

1. United Nations Children's Fund. Female Genital Mutilation/Cutting: a Global Concern Unicef'S Data Work on Fgm/C Support for Data Collection Data Analysis and Dissemination. Unicef. 2016. https://www.unicef.org/media/files/FGMC_2016_brochure_final_UNICEF_SPREAD.pdf.

2. World Health Organization. WHO Guidelines on the management of health complications from female genital mutilation. 2016:64.

3. Koski A, Heymann J. Changes in support for the continuation of female genital mutilation/cutting and religious views on the practice in 19 countries. Glob Public Health. 2019;14(5):696-708. doi:10.1080/17441692.2018.1542016

4. Farage MA, Miller KW, Tzeghai GE, Azuka CE, Sobel JD, Ledger WJ. Female genital cutting: Confronting cultural challenges and health complications across the lifespan. Women's Heal. 2015;11(1):79-94. doi:10.2217/whe.14.63

5. Berg RC, Denison E. A Tradition in Transition: Factors Perpetuating and Hindering the Continuance of Female Genital Mutilation/Cutting (FGM/C) Summarized in a Systematic Review. Health Care Women Int. 2013;34(10):837-859. doi:10.1080/07399332.2012.721417

6. Berg RC, Underland V, Odgaard-Jensen J, Fretheim A, Vist GE. Effects of female genital cutting on physical health outcomes: a systematic review and meta-analysis. BMJ Open. 2014;4(11):e006316. doi:10.1136/bmjopen-2014-006316

7. WHO. WHO / Care of Girls and Women Living with Female Genital Mutilation.; 2018. http://www.who.int/reproductivehealth/publications/health-care-girls-women-living-with-FGM/en/.

8. Goldberg H, Stupp P, Okoroh E, Besera G, Goodman D, Danel I. Female Genital Mutilation / Cutting in the United States: Updated Estimates of Women and Girls at Risk , 2012. Public Health Rep. 
2016;131(April):340-347.

9. Johnson-Agbakwu CE, Manin E. Sculptors of African Women's Bodies: Forces Reshaping the Embodiment of Female Genital Cutting in the West. Arch Sex Behav. 2020;(0123456789). doi:10.1007/s10508-020-01710-1

10. Ogunsiji O. Female Genital Mutilation (FGM): Australian Midwives' Knowledge and Attitudes. Health Care Women Int. 2015;36(11):1179-1193. doi:10.1080/07399332.2014.992521

11. Dawson AJ, Turkmani S, Varol N, Nanayakkara S, Sullivan E, Homer CSE. Midwives' experiences of caring for women with female genital mutilation: Insights and ways forward for practice in Australia. Women Birth. 2015;28(3):207-214. doi:10.1016/j.wombi.2015.01.007

12. Lazar JN, Johnson-Agbakwu CE, Davis OI, Shipp MP-L. Providers' perceptions of challenges in obstetrical care for somali women. Obstet Gynecol Int. 2013;2013:149640. doi:10.1155/2013/149640

13. Widmark C, Levál A, Tishelman C, Ahlberg BM. Obstetric care at the intersection of science and culture: Swedish doctors' perspectives on obstetric care of women who have undergone female genital cutting. J Obstet Gynaecol. 2010;30(6):553-558. doi:10.3109/01443615.2010.484110

14. Fawcett L, Maupin Jonathan N., Brewis Slade A, Johnson-Agbakwu CE. Somali Refugee Women and Their U.S. Healthcare Providers: Knowledge, Perceptions and Experiences of Childbearing. Somali Refug Women Their US Healthc Provid Knowledge, Perceptions Exp Childbear. http://hdl.handle.net/2286/R.I.25160.

15. Upvall MJ, Mohammed K, Dodge PD. Perspectives of Somali Bantu refugee women living with circumcision in the United States: A focus group approach. Int J Nurs Stud. 2009;46(3):360-368. doi:10.1016/j.ijnurstu.2008.04.009

16. Hamid A, Grace KT, Warren N. A Meta-Synthesis of the Birth Experiences of African Immigrant Women Affected by Female Genital Cutting. J Midwifery Womens Health. 2018:1-11. doi:10.1111/jmwh.12708

17. Brown E, Carroll J, Fogarty C, Holt C. "They Get a C-Section. They Gonna Die": Somali Women's Fears of Obstetrical Interventions in the United States. J Transcult Nurs. 2010;21(3):220-227. doi:10.1177/1043659609358780

18. Pavlish CL. Somali Immigrant Women and the American Health Care System. Soc Sci Med. 2010;71(2):353-361. doi:10.1016/j.socscimed.2010.04.010.Somali

19. Turkmani S, Homer CSE, Dawson A. Maternity care experiences and health needs of migrant women from female genital mutilation-practicing countries in high-income contexts: A systematic review and meta-synthesis. Birth. 2019;46(1):3-14. doi:10.1111/birt.12367

20. Mehta PK, Saia K, Mody D, et al. Learning from UJAMBO: Perspectives on Gynecologic Care in African Immigrant and Refugee Women in Boston, Massachusetts. J Immigr Minor Heal. 2017;20(2):1-8. doi:10.1007/s10903-017-0659-4

21. Zenner N, Liao LM, Richens Y, Creighton SM. Quality of obstetric and midwifery care for pregnant women who have undergone female genital mutilation. J Obstet Gynaecol (Lahore). 2013;33(5):459- 
22. Tunçalp, Were WM, Maclennan C, et al. Quality of care for pregnant women and newborns - The WHO vision. BJOG An Int J Obstet Gynaecol. 2015;122(8):1045-1049. doi:10.1111/1471-0528.13451

23. Straus L, McEwen A, Hussein FM. Somali women's experience of childbirth in the UK: Perspectives from Somali health workers. Midwifery. 2009;25(2):181-186. doi:10.1016/j.midw.2007.02.002

24. Odunukan OW, Abdulai RM, Hagi Salaad MF, Lahr BD, Flynn PM, Wieland ML. Provider and Interpreter Preferences Among Somali Women in a Primary Care Setting. J Prim Care Community Health. 2015;6(2):105-110. doi:10.1177/2150131914552846

25. Lundberg PC, Gerezgiher A. Experiences from pregnancy and childbirth related to female genital mutilation among Eritrean immigrant women in Sweden. Midwifery. 2008;24(2):214-225. doi:10.1016/j.midw.2006.10.003

26. Murray L, Windsor C, Parker E, Tewfik O. The Experiences of African Women Giving Birth in Brisbane, Australia. Health Care Women Int. 2010;31(5):458-472. doi:10.1080/07399330903548928

27. Vangen S, Johansen REB, Sundby J, Træen B, Stray-Pedersen B. Qualitative study of perinatal care experiences among Somali women and local health care professionals in Norway. Eur J Obstet Gynecol Reprod Biol. 2004;112(1):29-35. doi:10.1016/S0301-2115(03)00313-0

28. Brown E, Carroll J, Fogarty C, Holt C. “They Get a C-Section ... They Gonna Die”: Somali Women's Fears of Obstetrical Interventions in the United States. J Transcult Nurs. 2010;21(3):220-227. doi:10.1177/1043659609358780

29. Banke-Thomas A, Agbemenu K, Johnson-Agbakwu C. Factors Associated with Access to Maternal and Reproductive Health Care among Somali Refugee Women Resettled in Ohio, United States: A Cross-Sectional Survey. J Immigr Minor Heal. 2019;21(5):946-953. doi:10.1007/s10903-018-0824-4

30. Lane JL, Johnson-Agbakwu CE, Warren N, Budhathoki C, Cole EC. Female Genital Cutting: Clinical knowledge, Attitudes, and Practices from a Provider survey in the US. J Immigr Minor Heal. 2018;0(0):0. doi:10.1007/s10903-018-0833-3

31. Hess RF, Weinland J, Saalinger NM. Knowledge of female genital cutting and experience with women who are circumcised: a survey of nurse-midwives in the United States. J Midwifery Womens Health. 2010;55(1):46-54. doi:10.1016/j.jmwh.2009.01.005

32. Sharif Mohamed F, Wild V, Earp BD, Johnson-Agbakwu C, Abdulcadir J. Clitoral Reconstruction After Female Genital Mutilation/Cutting: A Review of Surgical Techniques and Ethical Debate. J Sex Med. 2020;17(3):531-542. doi:10.1016/j.jsxm.2019.12.004

33. Kaplan A, Torán-Monserrat P, Moreno-Navarro J, Castany Fàbregas MJ, Muñoz-Ortiz L. Perception of primary health professionals about female genital mutilation: from healthcare to intercultural competence. BMC Health Serv Res. 2009;9:11. doi:10.1186/1472-6963-9-11

34. Jacoby SD, Smith A. Increasing certified nurse-midwives' confidence in managing the obstetric care of women with female genital mutilation/cutting. J Midwifery Women's Heal. 2013;58(4):451-456. doi:10.1111/j.1542-2011.2012.00262. 
35. Leye E, Ysebaert I, Deblonde J, et al. Female genital mutilation: knowledge, attitudes and practices of Flemish gynaecologists. Eur J Contracept Reprod Health Care. 2008;13(2):182-190. doi:10.1080/13625180701780957

36. Sureshkumar P, Zurynski Y, Moloney S, Raman S, Varol N, Elliott EJ. Female genital mutilation: Survey of paediatricians' knowledge, attitudes and practice. Child Abuse Negl. 2016;55(April):1-9. doi:10.1016/j.chiabu.2016.03.005

37. Young J, Knuti K, Basel R, Agbakwu CJ. Female Genital Mutilation / Cutting - Pediatric Physician Knowledge, Training , and General Practice Approach American Academy of Pediatrics. J Immigr Minor Heal. 2019. doi:10.1007/s10903-019-00938-x

38. Relph S, Inamdar R, Singh H, Yoong W. Female genital mutilation/cutting: Knowledge, attitude and training of health professionals in inner city London. Eur J Obstet Gynecol Reprod Biol. 2013;168(2):195-198. doi:10.1016/j.ejogrb.2013.01.004

39. Cappon S, L'Ecluse C, Clays E, Tency I, Leye E. Female genital mutilation: Knowledge, attitude and practices of Flemish midwives. Midwifery. 2015;31(3):e29-e35. doi:10.1016/j.midw.2014.11.012

40. Eagly AH, Chaiken S. The advantages of an inclusive definition of attitude. Soc Cogn. 2007;25(5):582-602. doi:10.1521/soco.2007.25.5.582

41. Cappon S, L'Ecluse C, Clays E, Tency I, Leye E. Female genital mutilation: Knowledge, attitude and practices of Flemish midwives. Midwifery. 2015;31(3):e29-e35. doi:10.1016/j.midw.2014.11.012

42. Sureshkumar P, Zurynski Y, Moloney S, Raman S, Varol N, Elliott EJ. Female genital mutilation: Survey of paediatricians' knowledge, attitudes and practice. Child Abuse Negl. 2016;55(April):1-9. doi:10.1016/j.chiabu.2016.03.005

43. Kaplan A, Hechavarría S, Bernal M, Bonhoure I. Knowledge, attitudes and practices of female genital mutilation/cutting among health care professionals in The Gambia: a multiethnic study. BMC Public Health. 2013;13(1):851. doi:10.1186/1471-2458-13-851

44. Fitzgerald C, Hurst S. Implicit bias in healthcare professionals: A systematic review. BMC Med Ethics. 2017;18(1). doi:10.1186/s12910-017-0179-8

45. Hall WJ, Chapman M V., Lee KM, et al. Implicit racial/ethnic bias among health care professionals and its influence on health care outcomes: A systematic review. Am J Public Health. 2015;105(12):e60-e76. doi:10.2105/AJPH.2015.302903

46. Lee RT, Perez AD, Malik Boykin C, Mendoza-Denton R. On the prevalence of racial discrimination in the United States. PLoS One. 2019;14(1):1-16. doi:10.1371/journal.pone.0210698

47. Shen MJ, Peterson EB, Costas-Muñiz R, et al. The Effects of Race and Racial Concordance on Patient-Physician Communication: A Systematic Review of the Literature. J Racial Ethn Heal Disparities. 2018;5(1):117-140. doi:10.1007/s40615-017-0350-4

48. Martin AK, Tavaglione N, Hurst S. Resolving the conflict: Clarifying "vulnerability" in health care ethics. Kennedy Inst Ethics J. 2014;24(1):51-72. doi:10.1353/ken.2014.0005

49. Pajares F. Current Directions in Self-Efficacy Research. In: Maerh M, Pintrich PR, eds. Advances in Motivation and Achievement. 10th ed. Greenwich, CT: JAI Press; 1997:1-49. 
https://www.uky.edu/ eushe2/Pajares/effchapter.html.

50. Williams D, Rhodes RE. The Confounded Self-Efficancy Construct: Review, Conceptual Analysis, and Recommendations for Future Research. Health Psychol Rev. 2016;10(2):113-128. doi:10.1080/17437199.2014.941998

51. Howard MC. Introduction to Cronbach's Alpha. https://mattchoward.com/introduction-to-cronbachsalpha/. Accessed July 27, 2020.

52. Hair, J. F., Black, W. C., Babin, B. J., \& Anderson RE (2010). Multivariate Data Analysis. Pearson College Division; 2010.

53. Streiner DL. Starting at the beginning: An introduction to coefficient alpha and internal consistency. $J$ Pers Assess. 2003;80(1):99-103. doi:10.1207/S15327752JPA8001_18

54. Taber KS. The Use of Cronbach's Alpha When Developing and Reporting Research Instruments in Science Education. Res Sci Educ. 2018;48(6):1273-1296. doi:10.1007/s11165-016-9602-2

55. Leye E, Van Eekert N, Shamu S, Esho T, Barrett H. Debating medicalization of Female Genital Mutilation/Cutting (FGM/C): Learning from (policy) experiences across countries. Reprod Health. 2019;16(1):1-10. doi:10.1186/s12978-019-0817-3

56. Jacobs AJ, Arora KS. Punishment of Minor Female Genital Ritual Procedures: Is the Perfect the Enemy of the Good? Dev World Bioeth. 2017;17(2):134-140. doi:10.1111/dewb.12135

57. Doucet $\mathrm{M}-\mathrm{H}$, Pallitto C, Groleau D. Understanding the motivations of health-care providers in performing female genital mutilation: an integrative review of the literature. Reprod Health. 2017;14(1):46. doi:10.1186/s12978-017-0306-5

58. Atkinson HG, Ottenheimer D, Mishori R. Public Health Research Priorities to Address Female Genital Mutilation or Cutting in the United States. Am J Public Health. 2019;109(11):1523-1527. doi:10.2105/ajph.2019.305259

59. Earp BD. Between Moral Relativism and Moral Hypocrisy: Reframing the Debate on "FGM." Kennedy Inst Ethics J. 2016;26(2):105-144. doi:https://doi.org/10.1353/ken.2016.0009

60. Brady SS, Connor JJ, Chaisson N, Sharif Mohamed F, Robinson B "Bean" E. Female Genital Cutting and Deinfibulation: Applying the Theory of Planned Behavior to Research and Practice. Arch Sex Behav. 2019. doi:10.1007/s10508-019-1427-4

\section{Figures}


Scree Plot

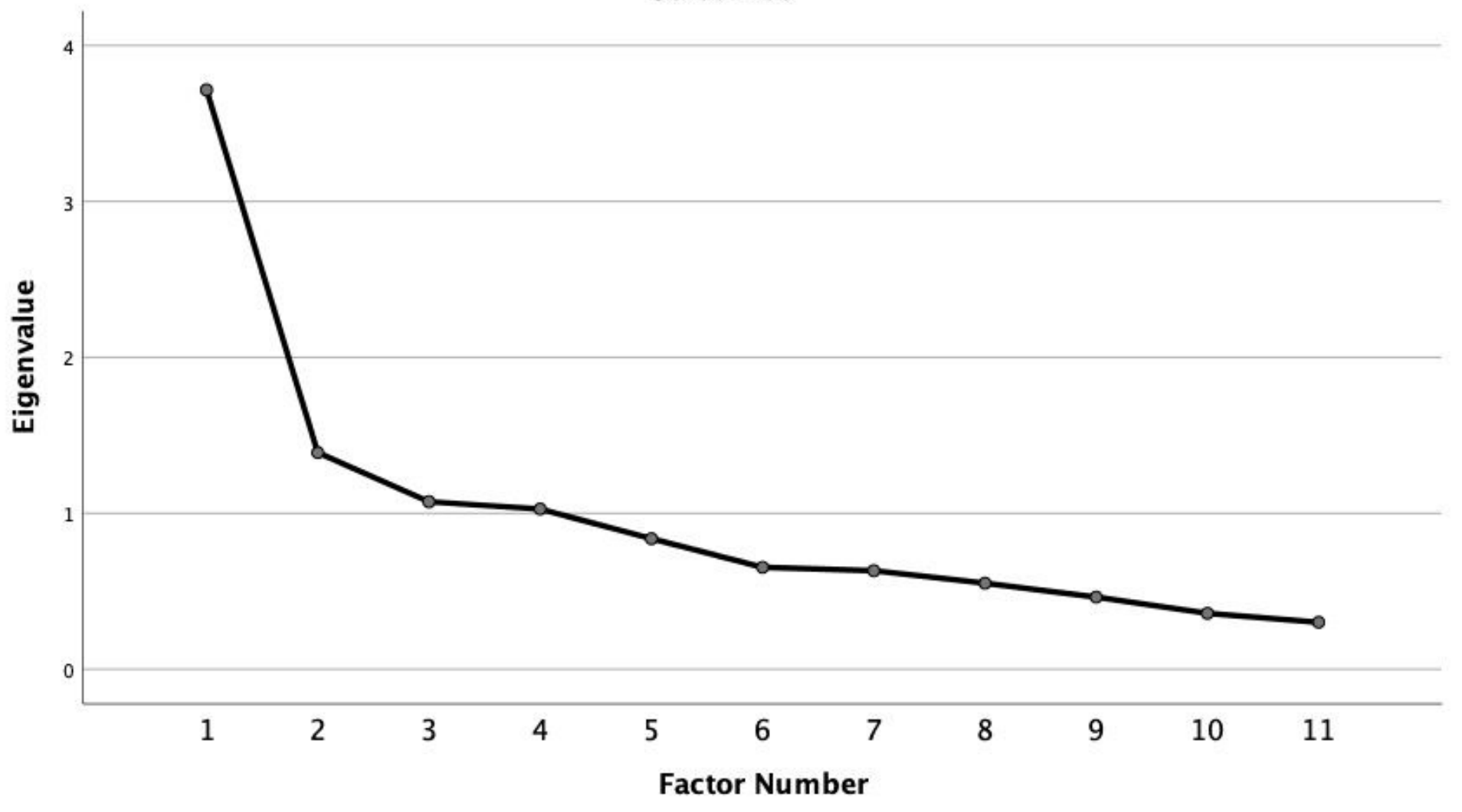

Figure 1

Scree Plot - Attitudes 


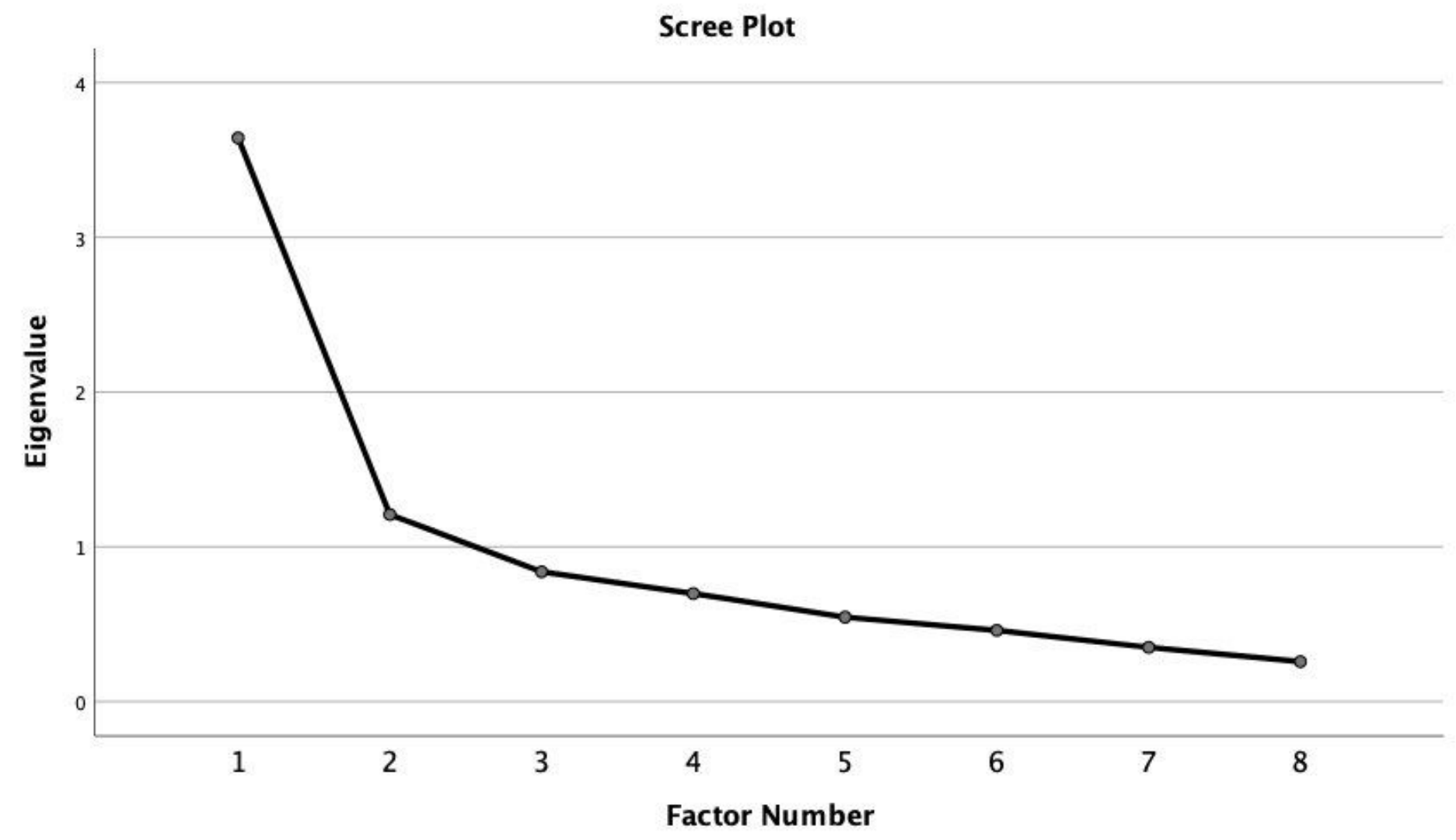

Figure 2

Scree Plot - Confidence

Page 28/28 